\title{
Modelling of Radiative Heat Transfer in Modelica with a Mobile Solar Radiation Model and a View Factor Model
}

\author{
Arnav Pathak, Victor Norrefeldt, Gunnar Grün \\ Fraunhofer Institute for Building Physics, Dept. Indoor Climate, 83626 Valley, Germany \\ arnav.pathak@ibp.fraunhofer.de, victor.norrefeldt@ibp.fraunhofer.de, \\ gunnar.gruen@ibp.fraunhofer.de
}

\begin{abstract}
This paper presents a model to estimate the solar radiation under clear sky conditions over stationary, moving as well as flying objects. For the latter it is important to predict the peak solar irradiance under clear sky condition to calculate maximum possible solar thermal loading. In this paper results of irradiation over surface on ground and over aircraft windows and windshields at cruise altitude are presented. Another model implemented, calculates the view factor between two or more surfaces. Determination of the long-wave radiant heat exchange between two or more surfaces or heat exchange with a surface itself requires a view factor matrix. There are several analytical solutions available to calculate view factors for simple and known configurations. Many building simulation programs estimate the view factors in a simplified way, especially when complex geometries are involved. The simplified approach may result in high errors of surface temperatures, which can further cause error in energy balance and estimation of comfort level. The purpose of creating this model is to calculate view factors between complex geometries. The view factor matrices of an enclosed space and of a geometry with openings on its surfaces are presented in this paper. A sensitivity analysis of a view factor matrix is also presented.
\end{abstract}

Keywords: Solar radiation modeling, View factor calculation, Modelica models, Long-wave radiant heat exchange

\section{Introduction}

Methods to predict solar radiation have a wide range of applications such as:

- Calculation of cooling loads for air conditioners

- Solar heat load on buildings, automobile, aircraft

- Material deterioration under sunlight

- Solar thermal power generation
Absorption and scattering of a solar beam in the atmosphere lead to attenuation of solar radiation. The outer space provides almost complete vacuum due to which there is no attenuation of solar radiation in the outer space. The main sources of absorption and scattering are atmospheric gases and aerosol in the atmosphere respectively. The longer the path travelled by a solar beam through the atmosphere before reaching the surface, the greater is the likelihood that more of it will be scattered or absorbed [1]. Especially for aircrafts the impact of solar radiation at cruise altitude can be high as radiation at cruise altitude can go up to $1200 \mathrm{~W} / \mathrm{m}^{2}$.

A further objective of this research work is to simulate long-wave radiant heat exchange between complex geometries. Thus the view factors between these geometries have to be determined. Calculation of view factors is a quite complex process, as it requires solving a double area integral. There are several analytical solutions available to calculate view factors for simple and known configurations [2]. In the procedure presented here a pre-processor does the triangular surface meshing and creates a file in stl-format which serves as input for the Modelica model. The results of different geometries are presented in this paper

\section{Solar Radiation Model}

The solar radiation model can be used to predict clear sky solar radiation over stationary surfaces like building façades or parked automobiles, moving surfaces like vehicles following a predefined path, as well as flying surfaces like aircraft during climb, cruise and descent.

There are two basic models:

- Sun position model

- Surface radiation model 


\subsection{Sun position model}

The sun position model is the global solar model which calculates the position of the sun in the sky at a particular time and at a particular location on the earth [6][7]. This information and the surface orientation are inputs to the surface irradiation model. Both models are set as an inner outer system, so there is no need of physically connecting them.

The input parameters for the global solar model depend on the type of application. If it is a stationary model, then the input parameters are longitude, latitude, altitude, standard time longitude, ground albedo, single scattering albedo, thickness of precipitable water $[\mathrm{cm}]$, ozone content of the atmosphere [cm NTP] and forward scatterance. Meaningful default values are implemented to allow simulations even if the user lacks some of this information (see Figure 1). Apart from above mentioned parameters the modeller must select the modelling approach from a drop down menu. There are three modelling approaches implemented to estimate radiation. If visibility data is not available the modeller can select between a modified Pinazo model [3][4] and a hybrid model for estimating global solar radiation [5]. If visibility data is available, the model will calculate angstrom's turbidity from this visibility data. Figure 1 shows the parameter window of the global sun position model for stationary surfaces.

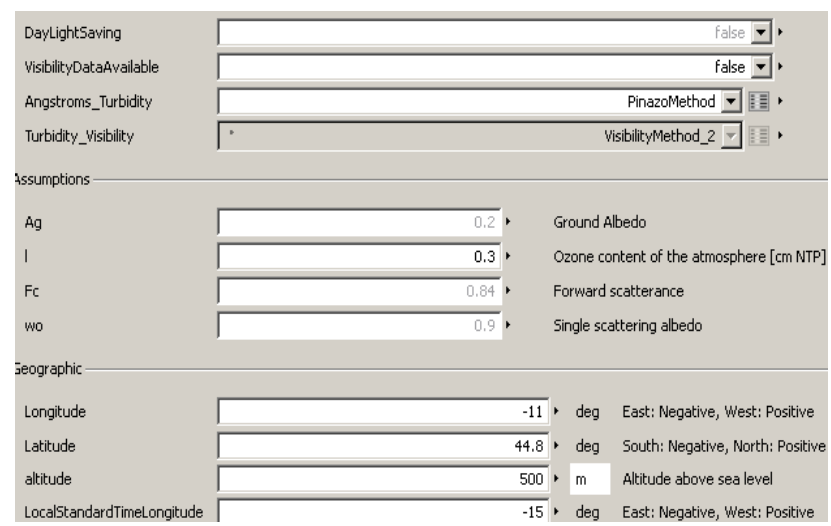

Figure 1 : Parameterization of stationary global sun position model

In case of moving or flying objects, the modeller has to use the mobile global sun position model. As location of a vehicle and orientation of surfaces are constantly changing, this information is set as input. Figure 2 shows the model block of the mobile global sun position model. All the variables changing with time are in the transition profile which is connected to the global model.

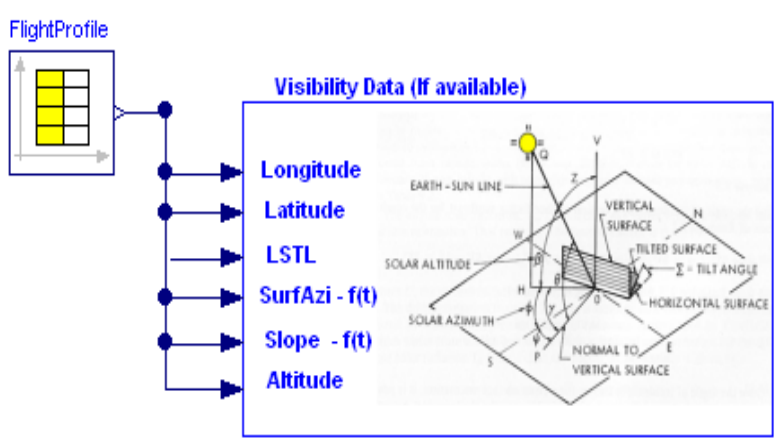

Figure 2 : Mobile sun position model connected with a flight profile

From the location, the day of the year and time of the day, the sun position model calculates the position of the sun in the sky and extraterrestrial radiation. From the altitude and the sun position in the sky, the model calculates the air mass. To determine the solar beam attenuation and irradiation on a horizontal surface, the model calculates absorption and scattering of a solar beam. The direct normal irradiance for a clear sky [3][4] is expressed as

$$
I_{n}=0.9751 . E_{o} I_{s c} \cdot t_{r} \cdot t_{a} \cdot t_{w} \cdot t_{o} \cdot t_{g}
$$

where $E_{o}$ is the earth's orbit eccentricity correction factor; $I_{s c}$ is the solar constant $\left(1367 \mathrm{~W} / \mathrm{m}^{2}\right) ; t_{r}, t_{a}, t_{w}$, $t_{o}$ and $t_{g}$ are the transmittance due to Rayleigh scattering, aerosol absorption and scattering, water vapour, ozone and other gases absorptions respectively.

To determine the direct solar radiation on horizontal surfaces using equation (1) it is necessary to know the value of Angstrom's turbidity coefficient. The model implemented will calculate angstrom's turbidity by three different methods. The modeller can select the method from a parameter window. If the horizontal visibility is known, the model computes the value of $B$ (Angstrom's turbidity coefficient) by equations (2) or (3) [9]:

$$
\beta=0.55^{a} \cdot\left(\frac{3.912}{V i s} \cdot 0.01162\right) \cdot\left(\frac{0.44 \cdot(V i s-5)}{18}+1.132\right)
$$

Equation (2) proves to be accurate enough when the value of particle size distribution exponent $a$ is 1.3. For the values of $a$ different to 1.3 equation (3) proves to be more accurate.

$\beta=\left(\frac{3.912}{V i s} 0.01162\right) .\{(16.23285+V i s) .(F-G \cdot a)+H\}$ 
Where

Vis $=$ Horizontal visibility $[\mathrm{km}]$

$\mathrm{F}=2.3575 \mathrm{E}^{-02}$,

$\mathrm{G}=9.387 \mathrm{E}^{-03}$ and

$\mathrm{H}=0.278863$

Equation (2) and (3) do not cover visibilities in fog. During fog, the size of the particles becomes very big hence none of these equations are applicable in that condition. The estimation of diffuse radiation is done by using modified Pinazo model [4].

\subsection{Surface radiation model}

Two types of surface models are implemented here, one is for stationary surfaces and the other is for moving as well as for flying surfaces. The modeller has to define the surface orientation of each surface in the surface model parameter window. If the surface is moving, then modeller has to give the initial surface orientation in the surface model and the change in surface orientation with time in the global model. The surface model reads the change in surface orientation from the global system and calculates the solar incident angle on each surface for each time step. Figure 3 shows the parameter window of the surface radiation model

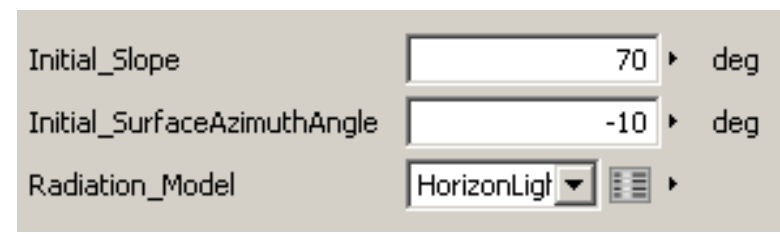

Figure 3: Surface radiation model parameter window

Four different radiation models are implemented [6]. The modeller has to select one of the following radiation models from the drop down menu,

- Isotropic model: All diffuse radiation is uniformly distributed over the sky dome.

- Circumsolar model: The effect of circumsolar radiation and horizon brightening is taken into account.

- Iso-circumsolar model: The portion of the diffuse radiation is treated as circumsolar and the remaining portion is treated as isotropic.

- Horizon brightening model: In addition to isotropic diffuse and circumsolar radiation, the Reindl model also accounts for horizon brightening.

When the model calculates clear sky radiation, the results of circumsolar model and isotropic model are the same. All four models are implemented to use under clear sky conditions as well as under overcast conditions. The surface radiation model can further be connected to wall models and/or window models.

\section{Estimated solar radiation}

\subsection{Stationary surface at ground}

Figure 4 shows a comparison between estimated solar radiation under clear sky conditions and the measured solar radiation. The measured data shown in the figure 4 were taken from Fraunhofer IBP's weather station for the $10^{\text {th }}$ of September 2011 [8].
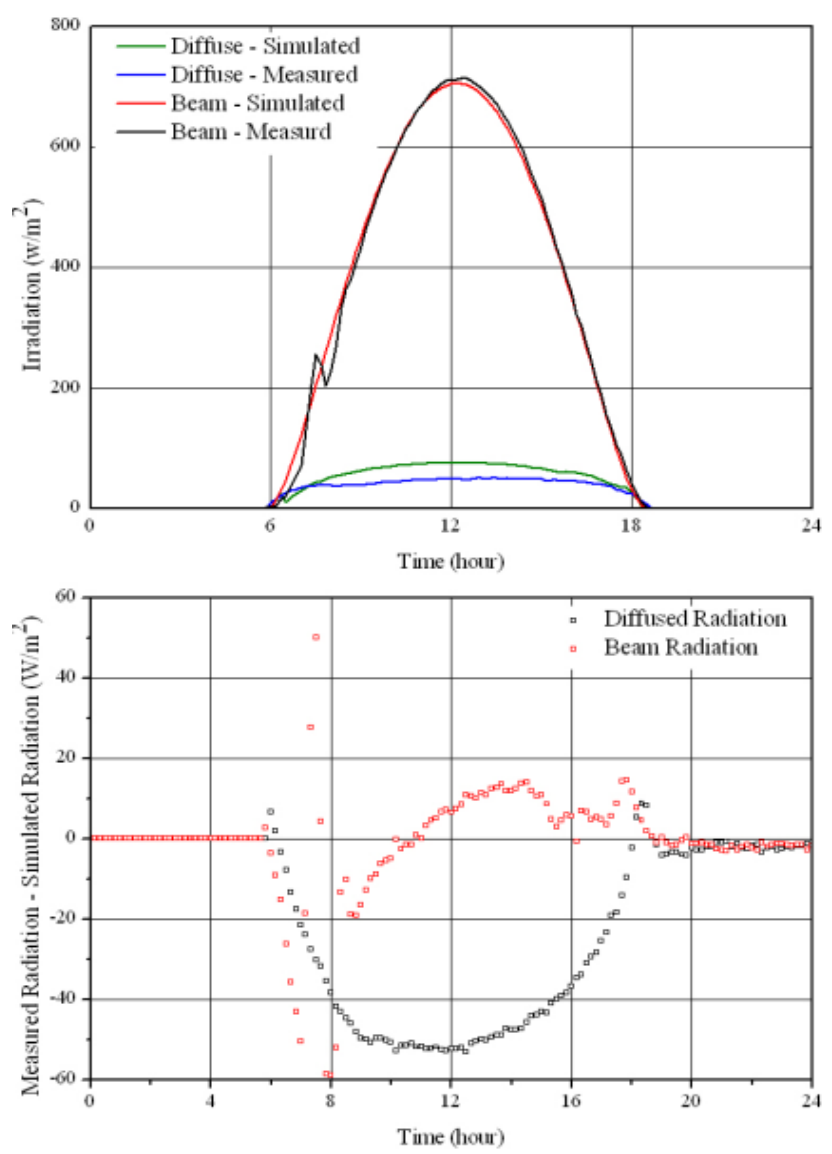

Figure 4 : Comparison of estimated radiation with measured radiation (top) and difference in measured and estimated radiation (bottom)

For almost the whole day, there were no clouds in the sky except for some time between $7 \mathrm{am}$ and $9 \mathrm{am}$, where one can see a larger deviation between measured and simulated beam radiation. This difference can be reduced if the cloud factor is known. The current model can calculate overcast conditions if the cloud factor is known in advance. For the clear sky condition, the difference between simulated and measured beam radiation is less than \pm $20 \mathrm{~W} / \mathrm{m}^{2}$. 


\subsection{High altitude solar radiation}

At cruise altitudes, solar radiation intensity is much higher because the solar beam has to travel less distance in the atmosphere.

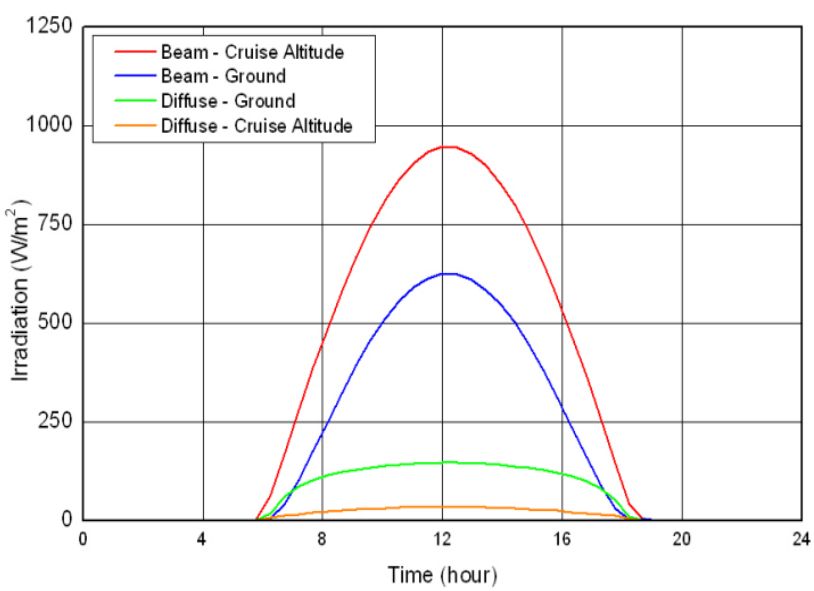

Figure 5: Ground level and high altitude solar radiation

Figure 5 shows the difference between the solar radiation on a horizontal surface at ground level (in Holzkirchen, Fraunhofer IBP, Germany) and at cruise altitude of $35,000 \mathrm{ft}$. Results shown are for the spring time. During hot summer days, solar radiation at cruise altitude can go up to $1200 \mathrm{~W} / \mathrm{m}^{2}$.

\subsection{Solar radiation on aircraft}

Solar heating can contribute significantly to thermal loads of an aircraft, especially when flying at high altitudes. Solar radiation affects e.g. aircraft cockpits directly through the windshield and cabins through windows. Heat dissipated by internal heat sources and heating by direct solar radiation has an adverse effect on thermal comfort of passengers, cabin crew and pilots which requires considerable amount of cooling air in the cabin and in the cockpit. When the aircraft is on ground at some hot and humid place the effect of solar heating is significant. While the aircraft is on ground, temperature of the surfaces exposed to direct solar radiation are typically $20 \mathrm{~K}$ higher than ambient temperature, depending on the thermal capacity of the surface material and geographic location. Figure 6 shows the global sun position model and environment model connected with a flight profile. It also shows a wall structure model and window model connected with the surface orientation model.

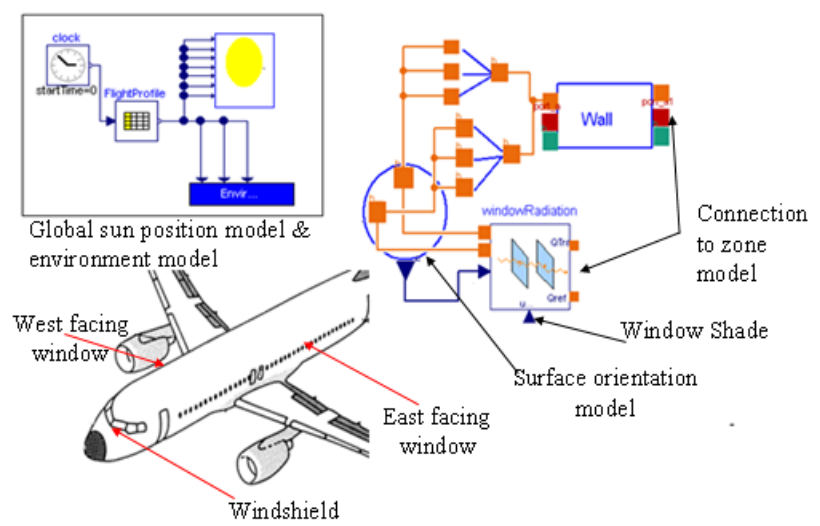

Figure 6 : Model to simulate solar radiation on an aircraft

The model shown in the figure 6 reads the flight profile (longitude, latitude, altitude, time, day of the year) and accordingly calculates the irradiation on differently oriented surfaces of the aircraft skin. The assumption of clear sky condition is fairly accurate and viable to use at cruise altitude, as there are not much clouds present at this altitude. Environmental parameters such as ambient pressure, ambient temperature, humidity, skin temperature etc. are implemented as functions depending on the flight profile.

The surface orientation model for the aircraft fuselage is a discretised cylinder model. The cylindrical surface is discretized into a number of rectangular strips where each strip has a different surface orientation and each strip is an individual surface which will calculate its new orientation as per its initial position and the given flight profile. The incident angle for each surface is different. This cylindrical surface model is then further connected to the window and wall model.

Figure 7 shows the solar irradiation on aircraft windows and windshield. The simulation is done for a flight from Munich international airport to Johannesburg international airport. There are several assumptions made such as: flight duration is $10 \mathrm{~h}$ $30 \mathrm{~min}$, departure time from Munich is $7 \mathrm{am}$, duration of taxing at departure airport and at arrival airport is ignored, initial take-off and approach is ignored. The simulation is done for 21-March, 21June and 21-Dec. It is assumed that the flight takes $30 \mathrm{~min}$ to reach cruise altitude and $45 \mathrm{~min}$ for descent and initial approach. The time to reach cruise altitude depends on the several factors like type of aircraft, weight of aircraft, allowable angle of attack and angle of turn etc. The flight profile considered here cannot be applied as a standard profile; it is 
purely based on close approximation. The cruise altitude considered for this simulation is $39,370 \mathrm{ft}$.

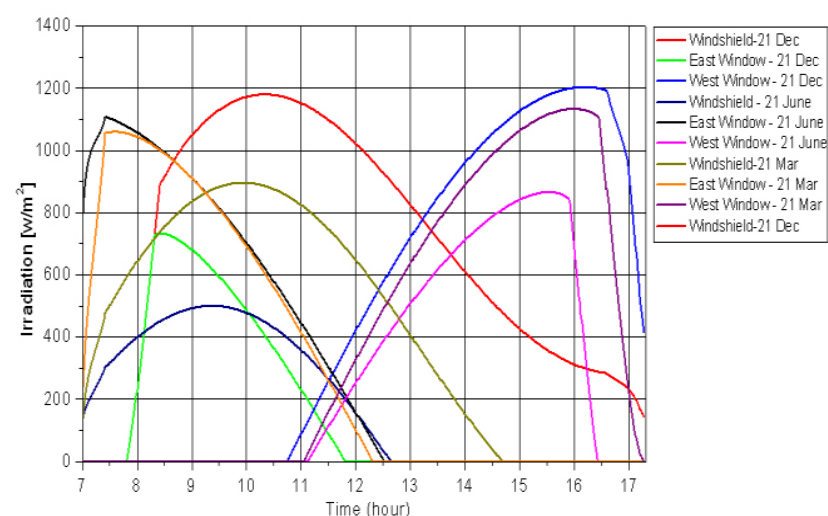

Figure 7 : Incoming solar radiation on window and windshield outer surface.

While observing the figure 7 , one should keep in mind that when it is winter in the northern hemisphere, it is summer in the southern hemisphere. The three dates considered in the simulation represent the summer solstice, winter solstice and equinox. The results shown in the figure 7 can be considered as irradiance over the outer surface of windshield and window, and not as the amount of irradiance entering into cockpit and cabin. The window and windshield will absorb some of the solar radiation, some of the radiation will be reflected and the remaining will be transmitted.

\section{View Factor Model}

\subsection{Basics}

View factors between two surfaces are dependent on the geometry of the surfaces and their orientation. The view factor can be interpreted as the fraction of diffusive radiant heat exchange between surface $\mathrm{i}$ and surface $\mathrm{j}$. The view factor between two infinitesimal surface elements $\mathrm{dA}_{\mathrm{i}}$ and $\mathrm{dA}_{\mathrm{j}}$ is defined by equation (4). [10][11]

$$
F_{i j}=\frac{1}{A_{i}} \int_{A i} \int_{A j} \frac{\cos \theta_{i} \cdot \cos \theta_{j}}{\pi \cdot r^{2}} d A_{i} d A_{j}
$$

Equation (4) is the general equation of a view factor between surface $\mathrm{i}$ and surface $\mathrm{j}$, as shown in figure 8 , where $r$ is the distance between the centres and $\cos \theta_{i}$ and $\cos \theta_{j}$ are the directional $\operatorname{cosines.} \operatorname{Cos} \theta_{i}$ and $\cos \theta_{j}$ can be determined by using following equation [11].

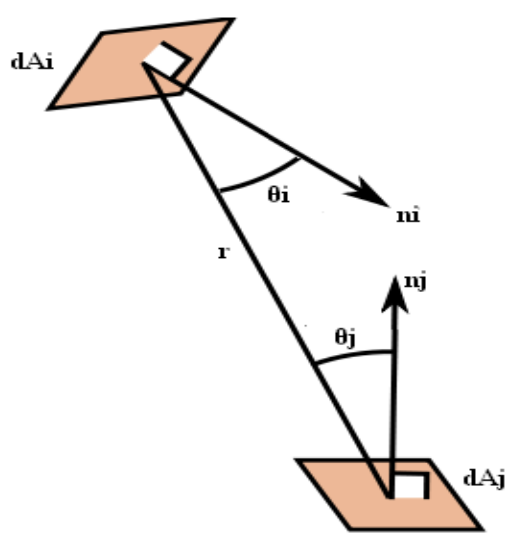

Figure 8: View factor between two infinitesimal surface elements

$\cos \theta_{i}=\frac{l_{i}\left(x_{j}-x_{i}\right)+m_{i}\left(y_{j}-y_{i}\right)+n_{i}\left(z_{j}-z_{i}\right)}{r}$

$\cos \theta_{j}=\frac{l_{j}\left(x_{i}-x_{j}\right)+m_{j}\left(y_{i}-y_{j}\right)+n_{j}\left(z_{i}-z_{j}\right)}{r}$

Where $\mathrm{x}, \mathrm{y}, \mathrm{z}$ are the coordinates of a centre of the element under consideration. When discretizing surfaces $i$ and $j$ with triangular elements to solve equation (4) the distance $r$ is determined from the centres of the triangles. The areas of the elements are determined using the parallelogram theorem. The discretization yields equation (7) :

$F_{i j}=\frac{1}{A_{i}} \sum \sum \frac{\cos \theta_{i} \cdot \cos \theta_{j}}{\pi \cdot r^{2}} \cdot d A_{i} d A_{j}$

Once $F_{i j}$ is known one can calculate $F_{j i}$ from equation (8):

$A_{i} \cdot F_{i j}=A_{j} \cdot F_{j i}$

\subsection{Modelling approach}

A pre-processor is used to create a triangular surface mesh and to store it as .stl-file. This file is the input for the Modelica model described here. The model reads vertex and normal vector of each triangular facet from the .stl-file and creates both coordinate matrix and normal vector matrix. In the next step, the model will calculate the centres of each triangle, the distance $r$ for each triangle with all the other triangles and similarly directional cosines for each triangle. The 'area function' call in the model will calculate area of each triangle. The 'view factor' function call in the model will calculate the view factor of each triangle with all the other triangles. 
Finally the 'sum view factors' function call will give the final view factor of the whole surface with all the other surfaces. Summation of view factors is done as shown in the equation (7). All of the above functions are implemented in a view factor model. The modeller has to give only the .stl-file for each surface.

\section{Application of view factor model}

\subsection{Closed geometry}

The accuracy of the model is dependent on the meshing size. With finer meshing the accuracy of results is improved. If the meshing is coarse, the results are less accurate but the model will take less computational time.

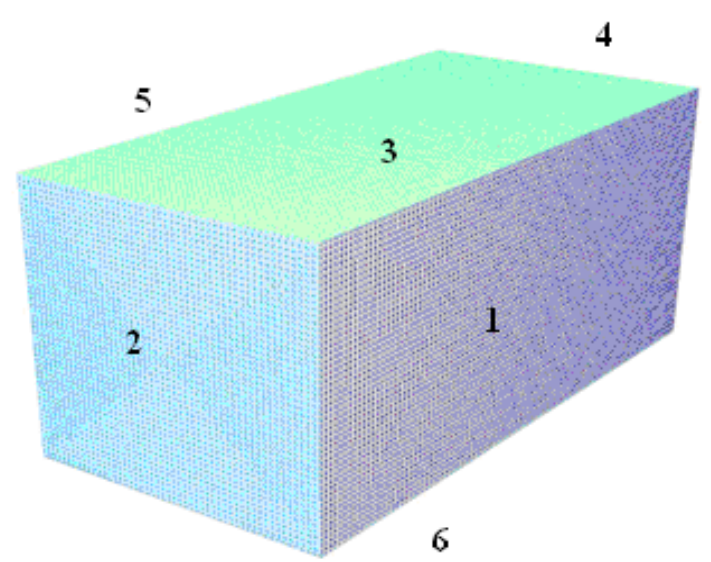

Figure 9 : Closed geometry (box)

Figure 9 shows a rectangular box with 6 surfaces. The box is $1 \mathrm{~m}$ long, $0.5 \mathrm{~m}$ high and $0.5 \mathrm{~m}$ wide. It is easy to solve the double area integral (DAI) for this geometry and that is the reason why such simple geometry is considered, so that the results of the Modelica model can be compared with the DAI solution. There are 6 surfaces of the box. Each surface of the box can see the other surface, so there will be 6x6 view factors but none of the surface can see itself as all the surfaces are flat surfaces hence there will be $6 \times 6$ view factors with a zeros on the diagonal of the view factor matrix. Table 1 shows the result of the Modelica model and the actual view factor values calculated by DAI and their comparison.
Table 1 : Comparison of view factors of a box meshed into 4000 triangles.

\begin{tabular}{|c|c|c|c|c|c|c|c|}
\hline & & 1 & $\begin{array}{l}\mathrm{e} \\
\%\end{array}$ & 2 & $\begin{array}{l}\mathrm{e} \\
\%\end{array}$ & 3 & $\begin{array}{l}\mathrm{e} \\
\%\end{array}$ \\
\hline \multirow[t]{2}{*}{1} & Modelica & 0.000 & \multirow{2}{*}{0.00} & 0.119 & \multirow{2}{*}{2.23} & 0.244 & \multirow{2}{*}{1.19} \\
\hline & DAI & 0.000 & & 0.116 & & 0.241 & \\
\hline \multirow{2}{*}{2} & Modelica & 0.238 & \multirow{2}{*}{2.21} & 0.000 & \multirow{2}{*}{0.00} & 0.238 & \multirow{2}{*}{2.21} \\
\hline & DAI & 0.233 & & 0.000 & & 0.233 & \\
\hline \multirow{2}{*}{3} & Modelica & 0.244 & \multirow{2}{*}{1.19} & 0.119 & \multirow{2}{*}{2.23} & 0.000 & \multirow{2}{*}{0.00} \\
\hline & DAI & 0.241 & & 0.116 & & 0.000 & \\
\hline \multirow{2}{*}{4} & Modelica & 0.238 & \multirow{2}{*}{2.21} & 0.069 & \multirow{2}{*}{0.03} & 0.238 & \multirow{2}{*}{2.21} \\
\hline & DAI & 0.233 & & 0.069 & & 0.233 & \\
\hline \multirow{2}{*}{5} & Modelica & 0.286 & \multirow{2}{*}{0.19} & 0.119 & \multirow{2}{*}{2.23} & 0.244 & \multirow{2}{*}{1.19} \\
\hline & DAI & 0.286 & & 0.116 & & 0.241 & \\
\hline \multirow{2}{*}{6} & Modelica & 0.244 & \multirow{2}{*}{1.19} & 0.119 & \multirow{2}{*}{2.23} & 0.286 & \multirow{2}{*}{0.19} \\
\hline & DAI & 0.241 & & 0.116 & & 0.286 & \\
\hline & & 4 & $\begin{array}{l}\mathrm{e} \\
\% \\
\end{array}$ & 5 & $\begin{array}{c}\mathrm{e} \\
\% \\
\end{array}$ & 6 & $\begin{array}{l}\mathrm{e} \\
\% \\
\end{array}$ \\
\hline \multirow{2}{*}{1} & Modelica & 0.119 & \multirow{2}{*}{2.23} & 0.286 & \multirow{2}{*}{0.19} & 0.244 & \multirow{2}{*}{1.19} \\
\hline & DAI & 0.116 & & 0.286 & & 0.241 & \\
\hline \multirow{2}{*}{2} & Modelica & 0.069 & \multirow{2}{*}{0.03} & 0.238 & \multirow{2}{*}{2.21} & 0.238 & 2.21 \\
\hline & DAI & 0.069 & & 0.233 & & 0.233 & \\
\hline 3 & Modelica & 0.119 & 2.23 & 0.244 & 1.19 & 0.286 & 0.19 \\
\hline & DAI & 0.116 & & 0.241 & & 0.286 & \\
\hline 4 & Modelica & 0.000 & 0.00 & 0.238 & 2.21 & 0.238 & 2.21 \\
\hline & DAI & 0.000 & & 0.233 & & 0.233 & \\
\hline 5 & Modelica & 0.119 & 2.23 & 0.000 & 0.00 & 0.244 & 1.19 \\
\hline & DAI & 0.116 & & 0.000 & & 0.241 & \\
\hline 6 & Modelica & 0.119 & 2.23 & 0.244 & 1.1 & 0.000 & 0.00 \\
\hline & DAI & 0.116 & & 0.241 & & 0.000 & \\
\hline
\end{tabular}

Results shown in table 1 are for a box meshed into 4000 triangles. The maximal error is $2.23 \%$ for $F_{12}$, $\mathrm{F}_{32}, \mathrm{~F}_{52}, \mathrm{~F}_{62}, \mathrm{~F}_{14}, \mathrm{~F}_{34}, \mathrm{~F}_{54}$ and $\mathrm{F}_{64}$. The minimal error is $0.03 \%$ for $\mathrm{F}_{24}$ and $\mathrm{F}_{42}$.

Table 2 shows the similar results as table 1 but with a bit finer meshing. The maximal error in table 2 is $0.57 \%$ and the minimal error is $0.01 \%$.

Table 2 : Comparison of view factors of a box meshed into 6000 triangles.

\begin{tabular}{|c|c|c|c|c|c|c|c|}
\hline & & 1 & $\begin{array}{c}\mathrm{e} \\
\%\end{array}$ & 2 & $\begin{array}{c}\mathrm{e} \\
\% \\
\end{array}$ & 3 & $\begin{array}{l}\mathrm{e} \\
\%\end{array}$ \\
\hline \multirow{2}{*}{1} & Modelica & 0.000 & \multirow{2}{*}{0.00} & 0.117 & \multirow{2}{*}{0.52} & 0.242 & \multirow{2}{*}{0.57} \\
\hline & DAI & 0.000 & & 0.116 & & 0.241 & \\
\hline \multirow{2}{*}{2} & Modelica & 0.234 & \multirow{2}{*}{0.49} & 0.000 & \multirow{2}{*}{0.00} & 0.234 & \multirow{2}{*}{0.49} \\
\hline & DAI & 0.233 & & 0.000 & & 0.233 & \\
\hline \multirow{2}{*}{3} & Modelica & 0.242 & \multirow{2}{*}{0.57} & 0.117 & \multirow{2}{*}{0.52} & 0.000 & \multirow{2}{*}{0.00} \\
\hline & DAI & 0.241 & & 0.116 & & 0.000 & \\
\hline \multirow[t]{2}{*}{4} & Modelica & 0.234 & \multirow{2}{*}{0.49} & 0.069 & \multirow{2}{*}{0.01} & 0.234 & \multirow{2}{*}{0.49} \\
\hline & DAI & 0.233 & & 0.069 & & 0.233 & \\
\hline
\end{tabular}




\begin{tabular}{|c|c|c|c|c|c|c|c|}
\hline \multirow{2}{*}{5} & Modelica & 0.286 & \multirow{2}{*}{0.08} & 0.117 & \multirow{2}{*}{0.52} & 0.242 & \multirow{2}{*}{0.57} \\
\hline & DAI & 0.286 & & 0.116 & & 0.241 & \\
\hline \multirow{2}{*}{6} & Modelica & 0.242 & \multirow{2}{*}{0.57} & 0.117 & \multirow{2}{*}{0.52} & 0.286 & \multirow{2}{*}{0.08} \\
\hline & DAI & 0.241 & & 0.116 & & 0.286 & \\
\hline & & 4 & $\begin{array}{l}\mathrm{e} \\
\%\end{array}$ & 5 & $\begin{array}{l}\mathrm{e} \\
\%\end{array}$ & 6 & $\begin{array}{c}\mathrm{e} \\
\%\end{array}$ \\
\hline \multirow{2}{*}{1} & Modelica & 0.117 & \multirow{2}{*}{0.52} & 0.286 & \multirow{2}{*}{0.08} & 0.242 & \multirow{2}{*}{0.57} \\
\hline & DAI & 0.116 & & 0.286 & & 0.241 & \\
\hline \multirow{2}{*}{2} & Modelica & 0.069 & \multirow{2}{*}{0.01} & 0.234 & \multirow{2}{*}{0.49} & 0.234 & \multirow{2}{*}{0.49} \\
\hline & DAI & 0.069 & & 0.233 & & 0.233 & \\
\hline \multirow{2}{*}{3} & Modelica & 0.117 & \multirow{2}{*}{0.52} & 0.242 & \multirow{2}{*}{0.57} & 0.286 & \multirow{2}{*}{0.08} \\
\hline & DAI & 0.116 & & 0.241 & & 0.286 & \\
\hline \multirow{2}{*}{4} & Modelica & 0.000 & \multirow{2}{*}{0.00} & 0.234 & \multirow{2}{*}{0.49} & 0.234 & \multirow{2}{*}{0.49} \\
\hline & DAI & 0.000 & & 0.233 & & 0.233 & \\
\hline \multirow{2}{*}{5} & Modelica & 0.117 & \multirow{2}{*}{0.52} & 0.000 & \multirow{2}{*}{0.00} & 0.242 & \multirow{2}{*}{0.57} \\
\hline & DAI & 0.116 & & 0.000 & & 0.241 & \\
\hline \multirow{2}{*}{6} & Modelica & 0.117 & \multirow{2}{*}{0.52} & 0.242 & \multirow{2}{*}{0.57} & 0.000 & \multirow{2}{*}{0.00} \\
\hline & DAI & 0.116 & & 0.241 & & 0.000 & \\
\hline
\end{tabular}

For a box with 8000 triangles (see table 3 ) the error is even less. The maximal error for a box meshed into 8000 triangles is $0.086 \%$ and the minimal error is $0.00 \%$. It is obvious that the error can be reduced by fine meshing but it would be interesting to see the effect of fine meshing on the computation time. Table 3 summarized results and indicates the needed computation time on an computer with - 'Intel $®$ Core TM i5, M 520@2.40 GHz, 2.92 GB RAM, Window 32-bit'

Table 3 : Result summary for view factor calculation

\begin{tabular}{|c|c|c|c|c|}
\hline $\begin{array}{c}\text { No of } \\
\text { Triangles }\end{array}$ & $\begin{array}{c}\text { Max } \\
\text { Error } \\
{[\%]}\end{array}$ & $\begin{array}{c}\text { Min } \\
\text { Error } \\
{[\%]}\end{array}$ & $\begin{array}{c}\text { Total } \\
\text { error of } \\
\text { closed } \\
\text { geometry } \\
{[\%]}\end{array}$ & $\begin{array}{c}\text { Computati } \\
\text { on time } \\
{[\mathrm{min}]}\end{array}$ \\
\hline 4000 & 2.233 & 0.030 & 1.10 & 34 \\
\hline 6000 & 0.566 & 0.013 & 0.40 & 86 \\
\hline 8000 & 0.086 & 0.000 & 0.05 & 170 \\
\hline
\end{tabular}

The geometry under consideration is symmetric. The computation time for non-symmetric geometries can be even higher. The meshing size is the defining factor one has to define as per the level of accuracy required and computational time.

\subsection{Geometry with openings}

Figure 10 shows the geometry with openings on surface 1 and surface 2 . The geometry shown in figure 10 is meshed into 4000 triangles. The results of a Modelica model are shown in table 4.

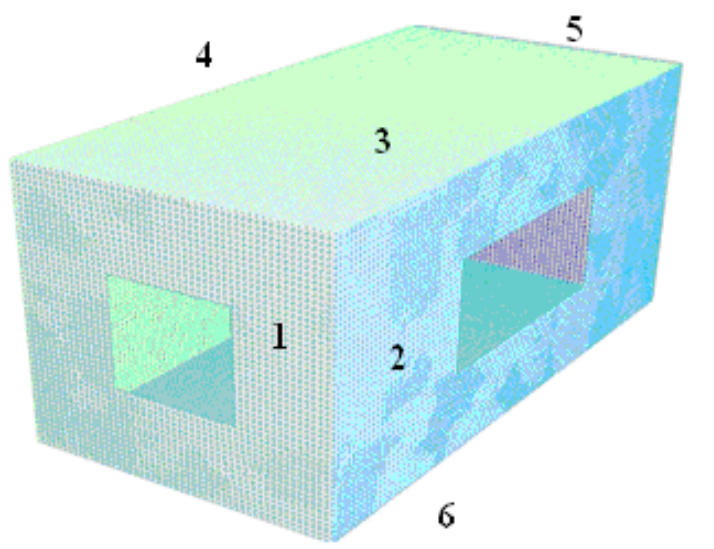

Figure 10 : Geometry with openings

The size of the rectangular box is the same as it was in the closed geometry. Therefore, only view factors concerning surface 1 and surface 2 will be different while all other results will be the same. The size of the opening on surface 1 is $0.2 \mathrm{~m} \times 0.2 \mathrm{~m}$ and on surface 2 is $0.2 \mathrm{~m} \times 0.4 \mathrm{~m}$.

Table 4 : View factor matrix for the geometry with openings on surface-1 and surface-2

\begin{tabular}{|c|c|c|c|c|c|c|}
\cline { 2 - 7 } \multicolumn{1}{c|}{} & 1 & 2 & 3 & 4 & 5 & 6 \\
\hline 1 & 0.000 & 0.215 & 0.240 & 0.240 & 0.068 & 0.240 \\
\hline 2 & 0.107 & 0.000 & 0.246 & 0.274 & 0.127 & 0.246 \\
\hline 3 & 0.101 & 0.207 & 0.000 & 0.244 & 0.119 & 0.286 \\
\hline 4 & 0.101 & 0.230 & 0.244 & 0.000 & 0.119 & 0.244 \\
\hline 5 & 0.057 & 0.213 & 0.238 & 0.238 & 0.000 & 0.238 \\
\hline 6 & 0.101 & 0.207 & 0.286 & 0.244 & 0.119 & 0.000 \\
\hline
\end{tabular}

\section{Conclusion \& Future Work}

A step towards better modelling of radiative heat transfers with Modelica has been taken in the presented work. An overview of the solar irradiation modelling for stationary, moving and flying surfaces is outlined in this paper. Comparison with weather data for a clear day shows that results of estimated clear sky radiation at ground level are accurate. A further model has been developed to determine the view factor between differently oriented surfaces. Comparison with an analytical solution shows that the accuracy increases with the number of surface elements used to discretize surfaces. For the future, we intend to include a model which can calculate obstructed view factors as well. Computational time is also an area of scrutiny where we intend to investigate solutions allowing for higher speed. These developments will allow for better modelling 
of radiative heat transfers when considering thermal management in stationary and mobile spaces.

\section{References}

[1] L.Elterman : UV, Visible and IR Attenuation for Altitudes to $50 \mathrm{~km}$, Air Force Cambridge Research Laboratories, L.G. NANSCOM FIELD, BEDFORD, MASSACHUSETTS, 1968.

[2] John R. Howell.: A Catalog of Radiation Heat Transfer Configuration Factors, $3^{\text {rd }}$ Edition, Department of Mechanical Engineering, The University of Texas at Austin, Visited on 16.March 2012 , http://www.engr.uky.edu/rtl/Catalog/

[3] J.M. Pinazo, J.Canada, J.V.Bosca.: A New Method to Determine Angstrom's Turbidity Coefficient: Its Application for Valencia, Solar Energy, Vol. 54, No. 4, pp. 219-226, 1995

[4] A.Q. Malik.: A modified method of estimating Angstrom's turbidity coefficient for solar radiation models, Renewable Energy 21 (2000) 537-552.

[5] K.Yang,G.W.Huang and N.Tamai.: A hybrid model for estimating global solar radiation, Solar Energy Vol. 70, No. 1, pp. 13-22, 2001

[6] Soteris A. Kalogirou : Slolar Energy Engineering Processes and Systems, Elsevier Inc, 2009.

[7] John A.Duffie, William A.Beckman.: Solar Engineering of Thermal Processes, John Wiley \& Sons. Inc. 1980.

[8] Fraunhofer IBP Weather Station Website, consulted on 06.March 2012, http://www.ibp.fraunhofer.de/wetter

[9] Meinrand A. Mächler: Parameterization of solar irradiation under clear skies, Diploma Maschineningenier, Eidg.Techn. Hochschule Zürich, 1977.

[10] Michael F. Modest, Radiative Heat Transfer Second Edition, Academic Press, Elsevier Science, 2003.

[11] Lilian Dobrowolski de Carvalho Augusto, Bruno Giacomet and Nathan Mendes.: Numerical Method for Calculating View Factor Between Two Surfaces, Proceedings: Building Simulation 2007 